University of Washington Tacoma

UW Tacoma Digital Commons

8-18-2017

\title{
Residential Mobility of Low-Income, Subsidized Households: A Synthesis of Explanatory Frameworks
}

\author{
Victoria Basolo \\ Anaid Yerena \\ University of Washington Tacoma, yerena@uw.edu
}

Follow this and additional works at: https://digitalcommons.tacoma.uw.edu/urban_pub

\section{Recommended Citation}

Basolo, Victoria and Yerena, Anaid, "Residential Mobility of Low-Income, Subsidized Households: A Synthesis of Explanatory Frameworks" (2017). Urban Studies Publications. 94.

https://digitalcommons.tacoma.uw.edu/urban_pub/94 


\title{
Residential Mobility of Low-Income, Subsidized Households: A Synthesis of Explanatory Frameworks
}

\begin{abstract}
Mobility, residential quality, and life outcomes are linked in the literature and these relationships have influenced low-income housing policy. This research investigates the determinants of mobility for households with a federal housing subsidy. Combining unique data from a survey of Housing Choice Voucher households, client program files, and secondary data, this study uses logistic regression to test several explanations for mobility, including the life cycle, housing market perceptions, and perceived and actual neighborhood conditions. The results indicate that a synthesis of explanations produce the best model to predict residential mobility. Neighborhood quality, perceived and actual, variables most strongly influence mobility, but life cycle factors and perception of the local housing market also impact moving choices. At the same time, the results suggest a gap in our understanding of the relationship among individuals' environmental perceptions, formation of feelings of neighborhood satisfaction, and actual neighborhood conditions. The article concludes with a discussion of the research and policy implications from this study.
\end{abstract}

KEY WORDS: mobility, low-income renters, residential satisfaction, neighborhoods, subsidized households

\section{Introduction}

Household residential mobility and residential location research, particularly of lowincome households, experienced renewed interest among social scientists beginning in the late 1980s and continues to the present. This research has been spurred by deconcentration strategies promoted by national governments, including the United States and countries in Europe (Kearns, 2012; Briggs, Comey \& Weismann, 2010; Stal \& Zuberi, 2010).

Variations in residential quality and access to resources have been associated with persistent spatial segregation between poorer, racial and ethnic minorities and more affluent whites, suggesting that mobility to less racially concentrated, higher quality neighborhoods might result in improved outcomes for poor, minority households (Clark, 2005; Johnson, Ladd, \& Ludwig, 2002; Rosenbaum, Reynolds, \& DeLuca, 2002; Skobba \& Goetz, 2013). Studies of federal housing programs such as Gautreaux, Moving to Opportunity (MTO), and HOPE VI, as 
well as research on the Housing Choice Voucher Program (HCVP), have examined the effects of mobility on low-income households (see, for example, Basolo, 2013, Goering \& Feins, 2003; Rosenbaum, 1995; Sink \& Ceh, 2011; Varady \& Walker, 2007). The results of these studies and related policy implications are plentiful and ideas about deconcentration and mobility continue to be updated and debated among researchers (see, for example, Clark, 2008; DeLuca, 2012; Darrah \& DeLuca, 2014; Goering, 2014; Moulton, Peck, \& Dillman, 2014; Imbroscio, 2012; Skobba \& Goetz, 2013; Walter, Li, \& Atherwood, 2015).

While the effects of mobility on low-income households has dominated recent research and the policy discourse among housing scholars, a second, related line of inquiry, has received attention and presents challenges to researchers supporting residential mobility and "choice" as policy imperatives. Comey, Briggs, \& Weismann (2008) note that many subsidized households, despite being encouraged or compelled to move to more desirable living environments by federal policy interventions, often move again, back to neighborhoods of lower quality. Furthermore, although the regular HCVP has not been studied as much as targeted federal interventions such as MTO, research indicates that with no or minimal intervention, voucher holders often locate in less desirable neighborhoods (Basolo \& Nguyen, 2005; McClure, Schwartz, \& Taghavi, 2015; Varady, 2010). One obvious explanation for locating in less desirable areas is an actual or perceived market barrier; in other words, the high cost of housing may severely limit voucher holders choices. However, actual and perceived market conditions may not be the only reason behind residential choices including the decision to move or not. Given existing research and policies, understanding the mobility decisions of low-income households should be a central concern of scholars and policymakers. 
Residential mobility research examines multiple explanations for moving and draws upon longstanding conceptualizations about mobility decisions and quantitative tests of related hypotheses (see, for example, Anderson, Leventhal, \& Dupéréde, 2014; Clark, 2013; De Groot, Mulder, \& Manting, 2011; Diaz-Serrano \& Stoyanova, 2010; Stockdale \& Catney, 2014; Speare, 1974), as well as a few qualitative investigations of the experiences of low-income households and their moving decisions (see, Briggs, Popkin, \& Goering, 2010; Darrah \& DeLuca, 2014; Rosen, 2015; Skobba \& Goetz, 2013; Teater, 2009).

In this article, we examine residential mobility in a sample of low-income households receiving housing vouchers. Given various explanations for mobility in the literature and the tendency for many subsidized low-income renters to move to lower quality neighborhoods, we use a synthetic model to investigate our central research question: What explains the residential mobility of low-income households with housing vouchers? Specifically, our model includes demographic, or life cycle/life stage variables as the base and we add actual neighborhood quality variables, followed by perceptions of the neighborhood and of the housing market. Using this approach, our main objective is to contribute to the literature by assessing the relative contribution of each variable and set of variables on mobility decisions. Our second objective is to inform the policy debate about residential choice and mobility of low-income, subsidized households.

The remainder of the article is divided into six sections. The first provides an overview of the mobility literature and the related residential satisfaction research. The second provides a brief overview of policy trends in the United States that link mobility with improved outcomes for lower income people. Third, we discuss the research design, methods, and data used in this study. The fourth section presents the analytic results, including the results of a set of nested 
logistic regression models. In the fifth section, we discuss the results from these models in more detail. Lastly, we conclude with the relevance of the results for research and policy and suggest directions for future work on residential mobility.

\section{Understanding Residential Mobility}

Residential mobility has been investigated by social scientists for decades. It has been studied by researchers interested in the moving decisions of individual households, as well as scholars concerned with the evolution and transformation of communities. The latter research is generally identified as neighborhood change analysis and captures race, ethnicity, income and physical transformations at the neighborhood level (for example, see Teernstra \& Van Gent, 2012; Farrell \& Lee, 2011; Goodsell, 2013; Lupton, 2003). Neighborhood change is an area of theoretical and policy interest to social scientists, but it focuses on the larger process of community transformation, rather than individual mobility, and therefore, is not of central interest to the discussion in this article. For this research, we are interested in individuals' decisions to move and, instead of thinking of neighborhood conditions as an outcome, we investigate how neighborhood conditions may influence individual residential mobility.

Research on residential mobility is abundant and reflects numerous disciplinary perspectives and policy themes. A substantial literature on mobility comes from the population studies perspective. This perspective employs demographic characteristics to predict mobility. Research along these lines has evolved over the years from a life stage (cycle) to a life course explanation of mobility with accompanying revisions to related quantitative models.

Nonetheless, these approaches clearly share a similar demographic focus.

An early contribution to mobility studies by Rossi (1955) provided evidence that demographic factors influence moves. In this study, the researcher interviewed a sample of 
households in Philadelphia and, using survey questionnaires, collected data on a range of variables such as household demographics, including tenure, and moving decisions. The analysis revealed that family size and composition, tenure (renter or owner), and ability to pay (an income constraint) all influenced mobility. Specifically, family size and composition influenced moves as households sought homes that accommodated these family characteristics. Homeowners tended to move less then renters, according to Rossi, because they had more control of their living environment and the transaction costs of moving was higher for them compared to renters. Lastly, household income limits residential choice to a family's ability to pay for housing (Rossi, 1955; Rossi \& Shlay, 1982). While this work was a bit slow to capture an enthusiastic audience, eventually it because a classic, influencing mobility research for many decades through to the present (DeGroot, et al, 2011; Rossi \& Shlay, 1982). In fact, this work would spur substantial research under the general theme of life cycle.

For decades, the life cycle explanation of mobility has dominated the literature. However, it is worth noting that multiple terms for the general idea of life cycle appear in the literature including life cycle, life stage, life span, and life course. In some cases, these terms are uniquely defined, while much of the time they are conflated or used interchangeably by researchers (O'Rand \& Krecker, 1990). This situation has led some researchers to suggest using the term that aligns with a researcher's disciplinary theoretical orientation (see Woolf, 1998); however, this proposition is not entirely satisfactory given mobility research is an interdisciplinary area of study and clarity across the disciplines would be useful in advancing knowledge about mobility. In this article, life cycle will be used in a general sense and understood to reflect demographic characteristics or events. We will briefly review the literature including conceptual extensions and empirical refinements to the life cycle model. 
Early studies of the life cycle and its relationship to mobility tended to find consistent results for two demographic variables. First, homeowners were found to be less mobile than renters. It is argued that homeowners invest more in place and have higher costs associated with moving. Second, as age increases, people are less likely to move (Pickvance, 1973; Quigley \& Weinberg, 1977; Simmons, 1968). In addition to life cycle, some of this research has shown mobility is less likely with time at a particular residence (see, for example, Speare, 1970).

In 1974, a competing explanation for residential mobility appeared in the literature. Aldon Speare argued that people move when residential stress, or some level of residential dissatisfaction, reaches an intolerable threshold. In other words, theoretically, Speare's work implies that individuals have housing and neighborhood preferences and will seek to satisfy these preferences to an acceptable level. His model relies on the perceptions of individuals about their living environment and their assessment of the fit between their preferences and their perceptions of their environment. This assessment is manifested as residential satisfaction. Importantly, Speare's model posits that background or demographic variables, such as individual or household characteristics, do not directly affect mobility, but rather they affect residential satisfaction, which, in turn, influences the desire to move, as well as actual moves (Speare, 1974). Speare's formulation turned attention to the concept of residential satisfaction and a significant body of work exists on this concept and ways to measure it.

Researchers have examined the components of residential satisfaction separately and in combination. Typically, operationalization of housing satisfaction involves residents' assessments of their housing quality (Hamersma, Tillema, Sussman, \& Arts, 2014; Spain, 1990; Varady \& Preiser, 1998), house size, and other dwelling unit characteristics (Addo, 2016; Buys \& Miller, 2012; James, 2008; Lu, 1999). Neighborhood satisfaction has generally been 
determined by residents' perceptions of neighborhood attributes such as overall property maintenance (Hur, Li, \& Terzano, 2015; Jagun et al., 1990), perceived safety (Bruin \& Cook, 1997; Buys \& Miller, 2012; Hur \& Nasser, 2014; Varady \& Preiser, 1998), public services (Ahlbrandt, 1984; Basolo \& Strong, 2002); and social cohesion and the number of family and friends in the neighborhood (Addo, 2016; Bruin \& Cook, 1997; Hamersma, Tillema, Sussman, \& Arts, 2014; Speare, 1974). Also, neighborhood satisfaction has been associated with distance to work/employment areas, transportation access, and proximity to shopping and other services (Addo, 2016; Hamersma, Tillema, Sussman, \& Arts, 2014; Michelson, 1977; Mohit, Ibrahim, \& Rashid, 2010). To capture the concept of neighborhood satisfaction for empirical studies, researchers typically ask subjects to assess some set of neighborhood characteristics and reduce these data to a composite measure (see Basolo \& Strong, 2002; Gruber \& Shelton, 1987). In many mobility studies, this multi-item variable is used to explain moving behavior.

Speare's mobility model has been tested many times with varying degrees of support. Some of this variation is due to inclusion and exclusion of different independent variables, both in a single specification and hierarchical models, as well as changes in the measurement of some variables (see, for example, Adriaanse, 2007; Amerigo \& Aragones, 1997; Landale \& Guest, 1985; Oh, 2003; Phinney, 2013); use of moving intention, actual intention or both as a dependent variable (DeGroot, et al., 2011); changes in model form (McHugh, Gober \& Reid, 1990); and region or country under study (Fang, 2006). Overall, support for the Speare conceptualization of mobility has been characterized as "modest" by some researchers, because residential satisfaction has been found to be a significant predictor of moving, but so have demographic or life cycle variables shown to have a direct effect on residential mobility ( $\mathrm{Lu}, 1998)$. 
The persistence and development of life cycle models situate them as the leading explanation of mobility in the literature. Past studies have shown that moving is negatively associated with aging, children in the household, and homeownership, while education and income are positively associated with mobility (Clark \& Dieleman, 1996; Coulter, Ham, \& Feijten, 2011; DiPasquale \& Wheaton 1996). This research has developed over time, confirming demographic variables affect moving behavior and, finding changes during the life cycle, such events as having children, getting a divorce, and aging are catalysts for mobility due to adjustments for household size and other needs (Clark, 2005; Clark, 2012a; Clark \& Onaka, 1983; Geist \& McManus, 2008; Kley, 2011). Age and tenure appear to be particularly consistent as predictors of mobility. A change in tenure, renter to owner, results in mobility, but stability of residence is typical of homeowners (Warner \& Sharp, 2016). In recent literature, researchers have included the quadratic for age to capture a potential curvilinear effect of aging on mobility. In these specifications, depending on the type and range of mobility under study, age and agesquared tend to be predictors of moving (See Clark, 2013; Clark \& Ledwith, 2006; Coulter, et al, 2011).

Life cycle models for planned and actual mobility sometimes consider the perceptions of households about their living environment, particularly their level of residential satisfaction. This research recognizes Speare's argument for satisfaction as an explanation of mobility and is generally complementary to the life cycle approach (Coulton, Theodos \& Turner, 2012). Studies combining life cycle factors and satisfaction (or dissatisfaction) in models typically show that satisfaction adds to the explanatory value of the life cycle model. In addition to satisfaction, a perception measure, some research includes actual measures of housing and neighborhood quality (Clark \& Ledwith, 2006; Coulter, et al., 2011; Lu, 1998). 
The mobility literature is expansive and has investigated many research questions. Examples of the variation in these studies include work focused on: unintended, voluntary, and involuntary moves (Clark \& Withers, 2007; DeLuca, Garboden, \& Rosenblatt; 2013; Fang, 2006); "moving up" by ethnic status (Clark, 2012b); specific age groups and within particular national contexts (Clark \& Maas, 2016, Isaacson, Michael, D’Ambrosio, Lisa, Tannistha, Samantha \& Joseph Coughlin, 2015; Kim, Woosnam, Marcouiller, \& Aleshinloye, 2015), and the relationship between moves and physical and mental well-being (Moulton et al., 2014; Oishi \& Schimmack, 2010).

Mobility models have been examined often for the general population. Fewer studies of the mobility of low-income households with government housing subsidies exist except for the research conducted on two unique initiatives, Gautreaux and Moving to Opportunity (MTO). In the next section, we briefly discuss this research and other work examining the mobility of households with subsidized housing.

\section{Mobility of Households with Subsidized Housing}

Over the last few decades in the United States, there has been a paradigmatic shift in housing policy. Some characteristics of this shift include a reduction in public housing, an increased reliance on housing vouchers, and the promotion of mobility to neighborhoods with less poverty concentration. Two important initiatives, Gautreaux and MTO, contributed to, and, in some instances spurred, moving poor households out of racially and poverty concentrated areas.

The Gautreaux initiative resulted from a 1966 class action suit alleging racial discrimination and racial segregation in the City of Chicago's public housing. The case dragged on, but in1976, the U.S. Supreme Court ruled in favor of the plaintiffs and ordered the Chicago 
Housing Authority to develop scattered site public housing that would avoid concentration of public housing in African American neighborhoods and also offer opportunities for African Americans to live in predominately White, suburban neighborhoods (See Polikoff, 2006 and Gill, 2012 for a more detailed discussion of the case).

The Gautreaux program resulted in thousands of low-income African American households moving from the inner city to predominately white suburbs. Using a quasiexperimental design, James Rosenbaum, a sociologist at Northwestern University, conducted extensive research on Gautreaux participants and reported a range of positive outcomes for these households. This research indicated that Gautreaux mover households experienced positive outcomes including higher levels of unemployment. In addition, compared to non-movers, the children of mover households had higher high school graduation and four-year college attendance rates, as well as were more likely to have relatively well compensated employment (Rosenbaum, Popkin, Kaufman, \& Rusin, 1991; Rosenbaum, 1993; 1995). Also, movers reported that their housing and neighborhood conditions greatly improved as a result of the move (Popkin \& Cunningham, 2002).

Findings from Gautreaux suggested mobility may provide an effective approach to improving the outcomes of the poor. However, the quasi-experimental design did not rule out all alternative explanations for outcomes and the focus on race deconcentration limited generalizability of the results. Therefore, the U.S. Department of Housing and Urban Development initiated the MTO demonstration in the early 1990s with an experimental design and a focus on income integration. The idea was to determine if moving from lower- to higherincome neighborhoods would have positive outcomes for poor households (see Goering \& Feins, 
2003 for a in depth discussion of the MTO study design and results from a set of evaluation studies).

Overall, the MTO program produced mixed results in terms of the outcomes for participants. In November 2011, the U.S. Department of Housing and Urban Development released the final findings from MTO (see Sanbonmatsu, Ludwig, Katz, Gennetian, Duncan, Kessler, Adam, McDade, \& Lindau, 2011). Some positive outcomes include better mental health outcomes for female youth and better physical health outcomes for adults in households that moved to higher income neighborhoods. The results did not indicate positive effects for employment or youth's education (Sanbonmatsu et al., 2011).

Mobility in the regular Housing Choice Voucher Program (HCVP) has not attracted as much attention from researchers compared to Gautreaux and MTO. Instead, research on the HCVP and other subsidized housing programs tends to examine the concentration of subsidized housing and the attributes associated with this type of housing's neighborhoods. Studies have found that voucher households tend to be concentrated in poorer neighborhoods (Devine, Gray, Rubin, \& Taghavi, 2003; Guhathakurta \& Mushkatel, 2000; McClure, Schwartz, \& Taghavi, 2015; Metzger, 2014) and in areas with lower performing schools (Horn, Ellen, \& Schwartz, 2014). The evidence, however, is mixed on the association between voucher locations and crime (Lens, 2014; see Mast \& Wilson, 2013).

The relatively limited research on mobility of voucher holders offers mixed results concerning improvement in households' outcomes. Basolo (2013) found no difference in neighborhood poverty rate, voucher holder employment status, or quality of public schools between movers and non-movers with vouchers. However, the neighborhoods of movers before and after their last move had slightly lower poverty rates, on average, and slightly better school 
quality. Interestingly, unemployment rates, on average, increased after mobility. Other research on mobility with vouchers indicates that mobility is associated with better neighborhoods after the move, but improvements are not positive across all groups within the voucher population (Basolo \& Nguyen, 2005; Varady \& Walker, 2003).

\section{Methodology, Data, and Variables}

This study examines mobility in a sample of low-income, subsidized renter households. The research question specifically asks: "What explains the mobility of these households?" To answer this question, the conceptual framework for this study begins with the life cycle model which identifies demographic factors as key determinants of mobility. To this base model, we add competing explanations for mobility including neighborhood satisfaction (the voucher holders' perceptions of their neighborhood environment), actual neighborhood quality measures, and the voucher holders' perceptions of housing supply or cost barriers in their market.

Data for studies of household mobility often are limited to small areas such as a set of neighborhoods and can be difficult and costly to collect (De Groot et al., 2011). This study uses a unique data set that encompasses Orange County, California, which has well over 500 neighborhoods (defined by census tract boundaries). Orange County, located directly south of Los Angeles County, covers almost 800 square miles of land (excludes water area) and is home to more than three million persons (U.S. Census Bureau, 2014). It is a demographically dynamic region characterized by growth and increasing diversity (Center for Demographic Research, 2010). Housing costs also have been and continue to be some of the highest in the nation for homeowners and renters (National Association of Home Builders, 2002; 2014; U.S. Department of Housing and Urban Development, 2002; 2014). As a result, lower-income households 
continue to face a high rent burden in Orange County (National Low Income Housing Coalition, 2016).

The population for this study includes over 8,000 low-income, Orange County residents who were receiving housing rental assistance (vouchers) under the administration of the Orange County Housing Authority (OCHA) during the survey period. The OCHA administratively oversees most of the county except for the cities of Anaheim, Santa Ana, and Garden Grove, which have their own housing authorities. OCHA voucher holders, however, live in these cities due to portability of the housing benefit and retention of voucher administration by the issuing agency (Basolo, 2003).

The OCHA cooperated on the study to ensure effective implementation of the survey. In consultation with the researcher, an OCHA data manager selected a random sample of approximately $25 \%$ of the voucher holder population $(n=2,010)$. Address information and available socio-demographic information on the sample households were provided to the researcher in a database file. The researcher assigned a unique tracking number to each case (address) in the file for a future merger to the primary survey data, as described below. A second file was created with only the address information and tracking number. This file was used to produce mailing labels for the survey questionnaire and correspondence.

The initial draft of the questionnaire was based on an instrument used in a previous study of neighborhood choice. The draft questionnaire was reviewed by OCHA staff and pretested on focus groups of voucher holders from two housing authorities, including OCHA. Minor modifications were made to the questionnaire based on the pretests. The revised version was then reviewed by OCHA staff and research assistants working on the study. The final questionnaire was produced in English, Spanish, and Vietnamese and the survey was conducted in 
approximately a six-month period, finishing in fall 2002. This time period precedes the housing market volatility associated with the Great Recession (beginning in 2007) and its aftermath. Thus, the data from this research are not confounded by this significant historical event. Also, it is important to note that the study is designed to test a research question about voucher holders and competing theoretical/conceptual frameworks at the individual household level. Data to do so is relatively scarce, but the data used in this research are an exception.

The mail survey followed recommendations from well-known research guides (Dillman, 1978; Mangione, 1995) on the development and implementation mail surveys. The process included questionnaire pretests, a co-signed survey introduction from the researcher and OCHA, and multiple follow ups to non-respondents. In addition, the researcher and graduate assistants administered approximately five questionnaires by phone. In these cases, the respondent requested this approach due to poor eyesight or language/literacy issues.

Respondents returned 1,267 completed questionnaires, a response rate of $63 \%$. While this response rate is very good for a mail survey, it raises a question about the possibility of response bias. Therefore, a logistic regression model with response versus no response as the dependent variable was specified using gender, race (white or not), ethnicity (Hispanic or not), dependent in home, the natural log of annual income, and the natural log of age as independent variables. The coefficients for gender, race, and age were statistically significant $(\mathrm{p}=.05)$. Specifically, respondents compared to non-respondents were: 1) more likely to be male; 2) less likely to be white; and 3) more likely to be older. In other words, the sample does not perfectly mirror the population of OCHA voucher holders. Therefore, the results may not be representative of this population and they should be interpreted cautiously and considered suggestive rather than definitive of the population. 
The survey data were merged with the OCHA data file ${ }^{1}$ and data from the U.S. Census Bureau to create a master database of variables. ${ }^{2}$ This dataset is used in our analyses.

Table 1 displays the variables used in the analyses in this article including their manner of measurement, mean, and standard deviation. However, further elaboration about measurement of a few variables is warranted. First, we assume that residents have perceptions about neighborhood quality, which are manifested in a level of neighborhood satisfaction. ${ }^{3}$ In other words, if they perceive better quality, then they will have higher levels of neighborhood satisfaction. We also assumed neighborhood satisfaction (or perceived quality) is a complex construct and is best captured by a composite measure. Thus, for this research, we constructed a 10-item index of neighborhood satisfaction. The items in the index were responses measured on a scale of 1 (very dissatisfied) to 10 (very satisfied) to questions about neighborhood characteristics of the current residence for non-movers and the previous residence for movers. The items in this additive index included queries about physical conditions of others' homes in the neighborhood, neighborhood cleanliness, neighborhood safety, quality of public schools, access to public transportation, access to parks/recreation, access to shopping, proximity to family, proximity to friends, and relations with neighbors. Together these indicators produce a robust and comprehensive measure and they are internally consistent as expressed in a Cronbach's alpha of 0.903 for the index.

Second, we also include two measures of actual neighborhood quality. These variables are based on 2000 U.S. Census data at the census tract level and include data from current neighborhoods for non-movers and previous neighborhoods for movers. The first measure is a single variable, percentage of overcrowding in the neighborhood, and is used a proxy for neighborhood conditions. Overcrowding as proxy was selected for two reasons: 1) city officials 
associate overcrowding with physical decline of structures, crime, graffiti and other negative outcomes (see Harwood \& Myers, 2002); and 2) overcrowding measures are readily available from the U.S. Census Bureau. The second measure, neighborhood economic distress, uses an additive index comprised of three indicators: the poverty rate, percentage of households on public assistance, and median family income (reflected) in the neighborhood. The Cronbach's alpha (0.85) indicates strong intercorrelations among the three indicators (the neighborhood conditions measures are discussed further in the next section).

Our analytic approach is a quantitative model that accounts for several alternative explanations for mobility and allows an assessment of the relative influence of these explanations, as well as individual variables. We use logistic regression ${ }^{4}$ with mobility (yes or no) as the dependent variable. Specifically, we asked voucher holders if they had moved in the last three years. Based on the literature, we expect life cycle variables, especially age, to influence mobility. Consistent with the literature, we anticipate as age of a householder increases, it is less likely a household moves. Other life cycle/demographic variables included in the model include gender, marital status, children present, race/ethnicity, education, and income. While homeownership has been found consistently to affect mobility, our sample is all renters, so this characteristic is not a concern in this research. We also expect voucher holders' neighborhood satisfaction (perceptions of the neighborhood) and neighborhood quality (measured with objective indicators) to influence mobility. Specifically, lower levels of satisfaction will be associated with moving, as will poorer quality neighborhoods. Finally, we expect a lack of available units in the housing market or a market barrier (as perceived by the voucher holder) reduces the likelihood of moving. In general, our expectation is that the 
synthesis of explanatory frameworks will produce the strongest model. However, we are not, a priori, hypothesizing which variables will have the most influence on mobility in our sample.

\section{Analysis and Results}

Our research investigates the moving behavior of a sample of low-income households with housing vouchers. We seek to contribute to the scholarly discourse on residential mobility of low-income, subsidized households and to inform a long standing policy debate about the role of residential choice and mobility in fostering better outcomes for poor households. For this reason, our research brings together several literatures and explanations for mobility, as discussed previously in this article, and we use results from multiple logistic regression models to assess the relative impacts of different explanations.

We preformed several preliminary analyses of the data prior to conducting the logistic regression analyses to assess our methodological rationale and choice of measures. For example, the selection of the neighborhood quality measures was critical to our objectives and this process involved multiple steps. First, we chose five actual quality indicators, three to represent neighborhood economic conditions and two for neighborhood physical conditions. ${ }^{5}$ Second, correlation analyses for these indicators and each satisfaction or perceived quality indicator was performed and the results are shown in Table 2. Two general results from these analyses are noteworthy. First, the correlation coefficients are rather small; in fact, not one of the coefficients between an actual and perceived quality indicator could be considered to represent even a moderate correlation. This result suggests the neighborhood perceptions of residents are not closely related to the "actual" quality or conditions measures used in research and policy. Second, two of the actual neighborhood physical conditions measures, the vacancy rate and the median age of housing, are virtually uncorrelated with the perceptual indicators; only perceived 
neighborhood homes physical conditions and median age of housing in the neighborhood are statistically significantly correlated, but the coefficients are quite small. Third, two reliability analyses, one for the three economic conditions indicators and another for the three physical conditions indicators were performed. The results of the economic conditions analysis supported combining these indicators into one index (see discussion in previous section), but the physical conditions indicators did not perform well as a composite measure. Following Speare's original formulation and the tendency for city officials to link overcrowding with numerous negative neighborhood outcomes including deteriorating structural conditions, we chose the single indicator of overcrowding as the actual physical conditions measure.

The neighborhood satisfaction index is a composite measure used as a proxy for neighborhood perceived quality. While the satisfaction indicators display high internal consistency, they may not necessarily be associated with mobility when considered individually. Therefore, prior to the regression analyses, we performed difference of means tests on each indicator to determine if movers and non-movers appeared to differ in their levels of neighborhood satisfaction. The results are shown in Table 3. The t-statistic for every analysis is statistically significant indicating there is a difference in the means of movers and non-movers for each satisfaction indicator.

Based on our preliminary analysis and study objectives, we chose a nested model approach for the logistic regression analysis. Specifically, we use hierarchical binary logistic regression because the dependent variable is dichotomous, whether a household moved or not in the last three years, and we are interested in assessing changes in model coefficients and model predictive value under various specifications representing different conceptual frameworks. Prior to discussing the models' results, we recognize a factor that is not accounted for in the analysis. 
It is possible that receiving a voucher prompts a move. The voucher program requires that the dwelling unit pass a physical inspection and the existing unit of the household approved for a voucher may not meet quality standards. Also, the voucher may make better quality housing in reach of the household. Thus, a voucher could be a trigger for the move. ${ }^{6}$ Our data do not allow us to test this hypothesis and we discuss it as a limitation later in the article.

We ran four models with the following introduction of independent variables: 1) life cycle with length in neighborhood; 2) Model 1 plus actual neighborhood quality variables; 3) Model 2 plus the perceived market constraint variable; and 4) Model 3 plus the neighborhood satisfaction (perceived neighborhood quality). We ran these models with the inclusion of age and age-squared to determine if the quadratic term would contribute to the model as has been hypothesized in life course models. The coefficient for age-squared was not statistically significant and other results remained virtually the same ${ }^{7}$ (see Table A in the appendix), so we chose to exclude age-squared from our final models (see Table 4 for these results).

Model 1 with life cycle factors and length of residence as independent variables produced three statistically significant coefficients at $p \leq .05$ : age, presence of child in the household, and length in neighborhood. All of these variables are negatively associated with mobility. The model chi-square is statistically significant $(\mathrm{p}=0.000)$. The next model $(2)$ includes the two actual neighborhood quality variables. The coefficients for both of these quality measures are statistically significant at $\mathrm{p} \leq .01$. The coefficient for neighborhood economic distress indicates that as economic conditions worsen, households are less likely to move. This result is unexpected and will be discussed later in the article. The results for overcrowding are as expected; as neighborhood overcrowding increases, households are more likely to move. The coefficients for age, presence of child, and length in neighborhood remain statistically significant 
$(\mathrm{p} \leq .05)$. The model chi-square is statistically significant but we are most interested in determining if there is improvement in prediction with the addition of the actual quality measures. The Nagelkerke $\mathrm{R}^{2}$ values shown in Table 4 can be compared across the models. Model 2 shows an increase (.171 to .197) associated with inclusion of the actual neighborhood quality variables. We also performed the likelihood ratio test (LRT) using chi-square based on the difference in the negative two log-likelihood values (-2LL) from Model 1 and Model 2 (the nested model chi-square) and it was statistically significant at $\mathrm{p}=.01$ confirming that Model 2 is a better fit (see Table A-2 in the appendix for -2LL changes with additions to models). The third model introduces the perceived market constraint variable as a predictor of mobility. The coefficient for this variable has the expected negative sign indicating that the perception of a market constraint may inhibit mobility; however, it is not statistically significant at the $\mathrm{p}=.05$ level, but is significant if $\mathrm{p}=.10$ is used as the criterion. The LRT or nested model chi-square (Model 3 compared to Model 2) is also significant at $\mathrm{p}=.10$. The results for other predictor variables remain similar to the previous nested models, although the p-value for the age coefficient fell just outside the .05 level and therefore, is shown as statistically significant at $\mathrm{p}=.10$.

The final specification, Model 4, includes the neighborhood satisfaction (perceived neighborhood quality) variable. The coefficient is highly statistically significant and has the expected negative sign. That is, as quality (satisfaction) increases, a household is less likely to have moved in the last three years; specifically, interpreting the odds ratio of .974 , a one unit increase in neighborhood satisfaction decreases the odds of moving by about $2.6 \%$. The Nagelkerke $\mathrm{R}^{2}$ increases from .200 to .245 and the results from the LRT show the nested model chi-square (difference between Model 3 and 4) is highly statistically significant indicating Model 
4 is the best model. Again, the substantive results for other independent variables remain similar to the previous models (the values for exponentiated coefficients of all significant variables in the full model are shown in Table 5).

The relative influence of each variable on mobility in Model 4 may be assessed using standardized regression coefficients (SRC). SRCs in logistic regression are a more complicated matter than in ordinary least squares regression. However, several approaches have been developed to calculate SRCs, including partially and fully standardized coefficients, but agreement on a single correct approach does not exist and the results from different approaches are not necessarily consistent (King, 2007; Long, 1997; Menard, 1995). For this reason, we calculated both partially standardized and fully standardized regression coefficients for the statistically significant variables in the full model using the formula provided by King (2007) for the former and the formula suggested by Menard (1995) for the latter. ${ }^{8}$ While the numerical values of the SRCs are not the same, the relative values for the variables of interest are similar (see Table 5). Length of residence in the neighborhood has the most influence, which is not a surprising finding. This variable may capture attachment to the residential environment, resistance to change or have a complex relationship with neighborhood satisfaction. ${ }^{9}$ For the actual and perceived neighborhood quality variables, the SRCs indicate that neighborhood economic distress has the strongest influence on mobility, followed by overcrowding in the neighborhood and lastly, neighborhood satisfaction (perceived quality). These results are unexpected and will be considered further in the discussion section. Presence of a child, perceived market constraint or barrier, and age follow in relative influence.

The results of the quantitative analysis provide support for a synthesis of explanatory frameworks when studying mobility of low-income, subsidized households. However, they also 
raise numerous issues about policies encouraging residential choice and mobility as mechanisms for improving living environments and livelihoods. In the next section, we discuss these issues, while elaborating on the results and their significance in light of the research objectives.

\section{Discussion}

The results from the quantitative analyses suggest that residential mobility is a behavior based on a complex amalgam of life cycle, perceived and actual physical and social neighborhood conditions, as well as perceptions about the housing market. This finding addresses our main research objective to contribute to the literature by assessing the relative contribution of the various explanations for mobility and the relative influence of each variable drawn from these frameworks. Our results support a model including multiple explanations for mobility and find for this sample of voucher holders, neighborhood quality variables, actual and perceived, noticeably boosted the fit from the base model, while perceived market constraint also did so, but to a much lesser extent. In examining the relative influence of individual variables, in addition to length of residence, both measures of actual neighborhood quality and neighborhood satisfaction are the most influential in predicting mobility, while market perception and life cycle variables (age and child present) are less influential.

Our results are not definitive, but instead provoke additional questions and issues. For example, perceived neighborhood quality as measured by the neighborhood satisfaction index increases the model's predictive power significantly with the largest chi-square change of the nested models. Thus, it might be tempting to assume that perceived neighborhood quality is a stronger predictor of mobility than actual neighborhood quality; however, as discussed the standardized regression coefficients indicate that both measures of actual quality are stronger predictors of mobility than perceived quality. 
These findings reveal a number of issues when predicting mobility. While neighborhood satisfaction is a predictor of mobility, it is unclear, based on our results, how the feeling of satisfaction is formed by individuals. We argued that satisfaction could be used as a measure of perceived neighborhood quality, because we reasoned neighborhood satisfaction is formed from an individual's impression of his environment. In other words, it is an individual's response or reaction to the quality of his residential environment. The data from our research, however, do not strongly support such an assertion. With weak correlations at best between satisfaction indicators and actual neighborhood quality measures, we conclude that individuals' levels of satisfaction must be formed by some other, less direct or perhaps more complex, cognitive process than initially assumed. Our data, however, cannot be dissected to understand the potential layers of meanings in the satisfaction indicators. Clearly, given the importance of neighborhood satisfaction in predicting mobility, research on the underlying process and characteristics that contribute to individuals' neighborhood satisfaction levels is critical to advancing theory in mobility studies.

The actual neighborhood quality measures present another issue. Both measures of actual quality (economic distress and overcrowding) influence mobility, however, the neighborhood economic distress variable is negatively associated with mobility. In other words, as economic conditions in the neighborhood worsen, residents with housing vouchers are less likely to move. This finding is not intuitive, but it may reflect the options available to poor households with vouchers. Because voucher policies limit the amount of rent a household can pay for their dwelling unit ${ }^{10}$, it is likely that voucher rent levels tend to be found in lower cost and poorer neighborhoods. Also, in some places, especially in tight markets such as our study area, voucher households may perceive a housing cost barrier and be more willing to locate in a poor 
neighborhood rather than lose the voucher assistance ${ }^{11}$, especially if the neighborhood satisfies other residential needs.

These findings also relate to our second objective to inform the policy debate about residential choice and mobility of low-income, subsidized households. They challenge public policy and its notion of choice and mobility as means to improve the lives of low-income households. Even if one accepts that mobility is the best route to a better life, housing voucher policy relies on households reading their environment, determining they are dissatisfied, choosing to move to a higher quality neighborhood, and encountering no perceived or actual barriers to moving. Given our results, additional research on the formation of environmental perceptions, actual quality measures and the relationship between these two types of measures in the context of low-income household mobility are critical to designing better policy. The finding that perceived housing availability may be a barrier to choice also could be related to voucher holders' being less likely to move even when living in neighborhoods that are more economically distressed. If perceptions do not match the reality of the housing market, then housing authorities must expand outreach and marketing to landlords, as well as voucher holders. However, if a housing market is undersupplied or tight, better integration of housing programs at the local level so that production is expanded and tied to other federal, state and local sources of subsidies would be a strong approach. A more innovative voucher program might promote more effective collaborations such that local housing authorities receive additional resources to work with low-income housing developers. This approach could guarantee a certain level of subsidy support in the form of vouchers for the development in return for quality location choice and maximizing the number of affordable units in the development. 
The study has several limitations which should be considered in interpreting its findings. First, our study population consisted of low-income renter households with a housing choice voucher administered by a local housing authority in one urban Southern California county. It may be that our results would not be replicated in other places. Second, the study was conducted in an area with a tight housing market and related high rental costs. Results may be different in a high vacancy, low rent area. Third, our study was cross-sectional and only looked at moves within a three-year period. A longitudinal study that spans many years, and potentially more than one move for any given household, may yield additional insights about the factors influencing mobility. In particular, a longitudinal study would allow an analysis of life changes such as having a child, going through a divorce, and other events which weigh into a residential location decision. Also, particular to the voucher population, a longitudinal study could capture periods before and after a household receives a voucher to better understand the effect that receiving this housing subsidy has on mobility.

\section{Conclusion}

The research in this article examined residential mobility from several different perspectives. The results indicate that for the population of low-income, subsidized households under study many factors influence mobility decisions including the life cycle, actual neighborhood quality, neighborhood satisfaction, and perceived housing market barriers.

Overall, our findings point to a need to better understand the meanings individuals assign to neighborhood characteristics and the cognitive process that forms neighborhood satisfaction from these meanings.

The findings from this research contribute to our knowledge of residential mobility decisions, as well as point to important gaps in mobility scholarship. This study provides 
evidence that existing theoretical and empirical models contribute to our understanding of moving decisions and the results suggest that a synthesis of explanations should be incorporated in mobility models. Moreover, further research investigating individuals' environmental perceptions and their formation of feelings of residential satisfaction is necessary to fully comprehend the process embodied in mobility models.

Finally, this study has implications for policy makers who favor residential choice and mobility as mechanisms to improve the lives of low-income households. Households in more economically distressed areas were less likely to move as were households who perceived a lack of homes to rent in their area. Both results suggest housing cost and availability impede choice and mobility. Evidence and conclusions from empirical studies (see, for example, McClure, Schwartz, \& Taghavi, 2015), including this study, indicate that the voucher program needs modifications before it can effectively promote mobility as a means for poverty deconcentration. 


\section{REFERENCES}

Addo, I.A. (2016) Assessing Residential Satisfaction among Low Income Households in MultiHabited Dwellings in Selected Low Income Communities in Accra, Urban Studies, 53(4), pp. 631-650.

Ahlbrandt, R.S., Jr. (1984) Neighborhoods, People, and Community (New York: Plenum Press).

Adriaanse, C.C.M. (2007) Measuring Residential Satisfaction: A Residential Environmental Satisfaction Scale (RESS), Journal of Housing and the Built Environment, 22(3), pp. 287-304.

Amerigo, M. \& Aragones, J.I. (1997) A Theoretical and Methodological Approach to the Study of Residential Satisfaction, Journal of Environmental Psychology, 17, pp. 47-57.

Anderson, S., Leventhal, T., \& Dupéré, V. (2014). Residential Mobility and the Family Context: A Developmental Approach, Journal of Applied Developmental Psychology, 35, pp. 70-78.

Basolo, V. (2013) Examining Mobility Outcomes in the Housing Choice Voucher Program: Neighborhood Poverty, Employment, and Public School Quality, Cityscape, 15(2), pp. 179-197.

Basolo, V. \& Nguyen M.T. (2005) Does Mobility Matter? The Neighborhood Conditions of Housing Voucher Holders by Race and Ethnicity, Housing Policy Debate, 16(3/4), pp. 297-324.

Basolo, V. (2003) Local Response to Federal Changes in the Housing Voucher Program: A Case Study of Intra-Regional Cooperation, Housing Policy Debate, 14(1/2), pp. 143-168.

Basolo, V. \& Strong, D. (2002) Understanding the Neighborhood: From Residents' Perceptions and Needs to Action, Housing Policy Debate, 13(1), pp. 83-105.

Briggs, X., Popkin, S.J., \& Goering, J. (2010) Moving to Opportunity: The Story of an American Experiment to Fight Ghetto Poverty, (New York, NY: Oxford University Press).

Briggs, X., Comey, J., \& Weismann, G. (2010) Struggling to Stay Out of High-Poverty Neighborhoods: Housing Choice and Locations in Moving to Opportunity's First Decade, Housing Policy Debate, 20(3), pp. 383-427.

Bruin, M.J. \& Cook, C.C. (1997) Understanding Constraints and Residential Satisfaction among Low-Income Single-Parent Families, Environment and Behavior, 29(4), pp. 532-553.

Buys, L. \& Miller, E. (2012) Residential Satisfaction in Inner Urban Higher-Density Brisbane, Australia: Role of Dwelling Design, Neighbourhood and Neighbours, Journal of Environmental Planning and Management, 55(3), pp. 319-338.

Center for Demographic Research. 2010. 2000-2010 Orange County Change Profile. Available at http://www.fullerton.edu/cdr/demographics/index.asp (accessed 14 June 2014). 
Clark, W.A.V. (2013) Life Course Events and Residential Change: Unpacking Age Effects on the Probability of Moving, Journal of Population Research, 30, pp. 319-334.

Clark, W.A.V. (2012a) Residential Mobility in the Housing Market in: D.F. Clapham, W.A.V. Clark, \& K. Gibb (Eds) The Sage Handbook of Housing Studies, pp. 66-83 (London: Sage Publications).

Clark, W.A.V. (2012b) Moving and Staying in Los Angeles Neighborhoods: Money Matters, but so Does Family Composition, Cityscape, 14(3), pp. 115-135.

Clark, W.A. V. (2008) Reexamining the Moving to Opportunity Study and its Contribution to Changing the Distribution of Poverty and Ethnic Concentration, Demography, 45(3), pp. 515535.

Clark, W.A.V. (2005) Intervening in the Residential Mobility Process: Neighborhood Outcomes for Low-Income Populations, Proceedings of the National Academy of Sciences of the United States of America, 102(43), pp.15307-15312.

Clark, W.A.V. \& Ledwith, V. (2006). Mobility, Housing Stress, and Neighborhood Contexts: Evidence from Los Angeles. Environment and Planning A, 38(6), pp. 1077-1093.

Clark, W.A.V. \& Dieleman, F.M. (1996) Households and Housing: Choice and Outcomes in the Housing Market (New Brunswick, N.J.: Center for Urban Policy Research).

Clark, W.A.V. \& Maas, R. (2016) Spatial Mobility and Opportunity in Australia: Residential Selection and Neighbourhood Connections, Urban Studies, 53(6), pp. 1317-1331.

Clark, W.A.V. \& Onaka, J.L. (1983). Life Cycle and Housing Adjustment as Explanations of Residential Mobility, Urban Studies, 20, pp. 47-57.

Clark, W.A.V. \& Withers, S. (2007) Family Migration and Mobility Sequences in the United States: Spatial Mobility in the Context of the Life Course, Demographic Research, 17, pp. 591622.

Comey, J., Briggs, X. \& Weismann, G. (2008). Struggling to Stay Out of High-Poverty Neighborhoods: Lessons from the Moving to Opportunity Experiment. Three-City Study of Moving to Opportunity, Brief 6 (Washington, DC: The Urban Institute).

Coulter, R., Ham, M., \& Feijten, P. (2011) A Longitudinal Analysis of Moving Desires, Expectations and Actual Moving Behavior, Environment and Planning A, 43, pp. 2742-2760.

Coulton, C., Theodos, B., \& Turner, M.A. (2012) Residential Mobility and Neighborhood Change: Real Neighborhoods under the Microscope, Cityscape, 14(3), pp. 55-89. 
Darrah, J. \& DeLuca, S. (2014) Living Here Has Changed My Whole Perspective: How Escaping Inner-City Poverty Shapes Neighborhood and Housing Choice, Journal of Policy Analysis and Management, 33(2), pp. 350-384.

De Groot, C., Mulder, C.H., \& Manting, D. (2011) Intentions to Move and Actual Moving Behavior in the Netherlands, Housing Studies, 26(3), pp. 307-328.

DeLuca, S., Garboden, P.M.E., \& Rosenblatt, P. (2013) Segregating Shelter: How Housing Policies Shape the Residential Location of Low-Income Minority Families, Annals of the American Academy of Political and Social Sciences, 647(1), pp. 268-299.

DeLuca, S. (2012) What is the Role of Housing Policy? Considering Choice and Social Science Evidence, Journal of Urban Affairs, 34(1), pp. 21-28.

Devine, D.J., Gray, R.W., Rubin, L., \& Taghavi, L.B. (2003) Housing Choice Voucher Location Patterns: Implications for Participants and Neighborhood Welfare (Washington, D.C.: U.S. Department of Housing and Urban Development).

Diaz-Serrano, L. \& Stoyanova, A.P. (2010) Mobility and Housing Satisfaction: An Empirical Analysis for 12 EU Countries, Journal of Economic Geography, 10, pp. 661-683.

Dillman, D.A. (1978) Mail and Telephone Surveys: The Total Design Method (New York: Wiley).

DiPasquale, D. \& Wheaton, W.C. (1996) Urban Economics and Real Estate Markets (Englewood Cliffs, N.J., Prentice Hall).

Fang, Y. (2006) Residential Satisfaction, Moving Intention and Moving Behaviours: A Study of Redeveloped Neighborhoods in Inner-City Beijing, Housing Studies, 21(5), pp. 671-694.

Farrell, C.R. \& Lee, B.A. (2011) Racial Diversity and Change in Metropolitan Neighborhoods, Social Science Research, 40(4), pp. 1108-1123.

Geist, C. \& McManus, P.A. (2008) Geographical Mobility over the Life Course: Motivations and Implications, Population Space and Place, 14(4), pp. 283-303.

Gill, A.M.K. (2012) Moving to Integration? The Origins of Chicago's Gautreaux Program and the Limits of Voucher-Based Housing Mobility, Journal of Urban History, 38(4), pp. 662-686.

Goering, J. (2014) The Unintended Imposition of Housing Deconcentration? Cityscape, 16(2), pp. 127-133.

Goering, J., \& Feins, J. (Eds) (2003) Choosing a Better Life: Evaluating the Moving to Opportunity Social Experiment (Washington, DC: Urban Institute Press). 
Goodsell, T.L. (2013) Familification: Family, Neighborhood Change, and Housing Policy, Housing Studies, 28(6), pp. 845-868.

Gruber, K.J., \& Shelton, G.G. (1987) Assessment of Neighborhood Satisfaction by Residents of Three Housing Types, Social Indicators Research, 19(3), pp. 303-315.

Guhathakurta, S. \& Mushkatel A.H. (2000) Does Locational Choice Matter? A Comparison of Different Subsidized Housing Programs in Phoenix, Arizona, Urban Affairs Review, 35(4), pp. 520-540.

Hamersma, M., Tillema, T., Sussman, J., \& Arts, J. (2014) Residential Satisfaction Close to Highways: The Impact of Accessibility, Nuisances and Highway Adjustment Projects, Transportation Research Part A, 59, pp. 106-121.

Harwood, S. \& Myers, D. (2002) The Dynamics of Immigration and Local Governance in Santa Ana: Neighborhood Activism, Overcrowding, and Land-Use Policy, Policy Studies Journal, 30(1), pp. 70-91.

Hipp, J.R. (2007) Block, Tract, and Levels of Aggregation: Neighborhood Structure and Crime and Disorder as a Case in Point, American Sociological Review, 72(5), pp. 659-680.

Horn, K.M., Ellen, I.G., \& Schwartz, A.E. (2014) Do Housing Choice Voucher Holders Live Near Good Schools? Journal of Housing Economics, 23, pp. 28-40.

Hur, M., Li, Y., \& Terzano, K. (2015) Breaking the Chain: Understanding the Association between Foreclosure Intensity and Neighborhood Satisfaction, Applied Geography, 58, pp. 7-17.

Hur, M. \& Nasser, J.L. (2014) Physical Upkeep, Perceived Upkeep, Fear of Crime and Neighborhood Satisfaction, Journal of Environmental Psychology, 38, pp. 186-194.

Imbroscio, D. (2012) Beyond Mobility: The Limits of Liberal Urban Policy, Journal of Urban Affairs, 34(1), pp.1-20.

Isaacson, M., D’Ambrosio, L., Tannistha, S. \& Coughlin, J. (2015) Life-Stage and Mobility: An Exploratory GPS Study of Mobility in Multigenerational Families, Ahmedabad, India, Journal of Aging \& Social Policy, 27, pp. 348-363.

Jagun, A., Brown, D.R., Milburn, N.G., \& Gary, L.E. (1990) Residential Satisfaction and Socioeconomic and Housing Characteristics or Urban Black Adults, Journal of Black Studies, 21(1), pp. 40-51.

James III, R.N. (2008) Residential Satisfaction of Elderly Tenants in Apartment Housing, Social Indicators Research, 89(3), pp. 421-437.

Johnson, M.P., Ladd, H.F. \& Ludwig, J. (2002) The Benefits and Costs of Residential Mobility Programmes for the Poor, Housing Studies, 17(1), pp. 125-138. 
Kearns, A. (2012) Mobility, Mixing, and Neighborhood Change: A British Perspective, Cityscape, 14(3), pp. 185-188.

Kim, H., Woosnam, K.M., Marcouiller, D.W., \& Aleshinloye, K. (2015) Residential Mobility, Urban Preference, and Human Settlement: A South Korean Case Study, Habitat International, 49, pp. 497-507.

King, J.E. (2007) Standardized Coefficients in Logistic Regression. Paper presented at the 2007 annual meeting of the Southwest Educational Research Association, San Antonio. Available at: http://www.ccitonline.org/jking/homepage/ (accessed 11 May 2014).

Kley, S. (2011) Explaining the Stages of Migration within a Life-course Framework, European Sociological Review, 27(4), pp. 469-486.

Landale, N.S. \& Guest, A.M. (1985) Constraints, Satisfaction and Residential Mobility: Speare's Model Reconsidered, Demography, 22(2), pp. 199-222.

Lens, M.C. (2014) The Impact of Housing Vouchers on Crime in US Cities and Suburbs, Urban Studies, 51(6), pp. 1274-1289.

Long, J.S. (1997) Regression Models for Categorical and Limited Dependent Variables (Thousand Oaks, CA: Sage Publications).

Lu, M. (1998) Analyzing Migration Decision making: Relationships between Residential Satisfaction, Mobility Intentions, and Moving Behavior, Environment and Planning A, 30(8), pp. 1473-1495.

Lu, M. (1999) Do People Move When They Say They Will? Inconsistencies in Individual Migration Behavior, Population and Environment, 20(5), pp. 467-488.

Lupton, R. (2003) Poverty Street: The Dynamics of Neighborhood (Bristol, UK: The Policy Press).

Maier, J. \& Kim, Y.J. (2008) Neighborhood Satisfaction and Dissatisfaction, Michigan Sociological Review, 22, pp. 171-195.

Mangione, T.W. (1995) Mail Surveys: Improving the Quality (Thousand Oaks, CA: Sage Publications).

Mast, B.D. \& Wilson, R.E. (2013) Housing Choice Vouchers and Crime in Charlotte, NC, Housing Policy Debate, 23(3), pp. 559-596.

McClure, K., Schwartz, A.F., \& Taghavi, L. B. (2015) Housing Choice Voucher Location Patterns a Decade Later, Housing Policy Debate, 25(2), pp. 215-233. 
McHugh, K.E., Gober, P., \& Reid N. (1990) Determinants of Short and Long-Term Mobility Expectations for Home Owners and Renters, Demography, 27(1), pp. 81-95.

Menard, S. (1995). Applied Logistic Regression Analysis (Thousand Oaks, CA: Sage Publications).

Metzger, M.W. (2014) The Reconcentration of Poverty: Patterns of Housing Voucher Use, 2000 to 2008, Housing Policy Debate, 24(3), pp. 544-567.

Michelson, W. (1977) Environmental Choice, Human Behavior, and Residential Satisfaction (New York: Oxford University Press).

Mohit, M.A., Ibrahim, M. \& Rashid, Y.R. (2010) Assessment of Residential Satisfaction in Newly Designed Public Low-Cost Housing in Kuala Lumpur, Malaysia, Habitat International, 34(1), pp. 18-27.

Moulton, S., Peck, L.R., \& Dillman, K.N. (2014). Moving to Opportunity's Impact on Health and Well-Being among High-Dosage Participants, Housing Policy Debate, 24(2), pp. 415-445.

National Association of Home Builders (2002) Economic and Housing Data. Available at http://www.nahb.com/facts/default.htm (accessed on 15 April 2003).

National Association of Home Builders (2014) Housing Data: State and Local Data. Available at http://www.nahb.org/reference_list.aspx?sectionID=132 (accessed 3 March 2015.

National Low-Income Housing Coalition (2016) Out of Reach 2016. Washington, D.C.: Author Available at: http://nlihc.org/sites/default/files/oor/OOR_2016.pdf (accessed June 11, 2016).

Oh, J. (2003) Social Bonds and the Migration Intentions of Elderly Urban Residents: The Mediating Effects of Residential Satisfaction, Population Research and Policy Review, 22(2), pp. 127-146.

Oishi, S., \& Schimmack, U. (2010) Residential Mobility, Well-Being, and Mortality, Journal of Personality and Social Psychology, 98(6), 980-984.

O'Rand, A.M. \& Krecker, M.L. (1990) Concepts of the Life Cycle: Their History, Meanings, and Uses in the Social Sciences, Annual Review of Sociology, 16, pp. 241-262.

Phinney, R. (2013) Exploring Residential Mobility among Low-Income Families, Social Service Review, 87(4), pp. 780-815.

Pickvance, C.G. (1973) Life-cycle, Housing Tenure and Intra-Urban Residential Mobility: A Causal Model, Sociological Review, 21, pp. 279-297.

Polikoff, A. (2006) Waiting for Gautreaux (Evanston, IL: Northwestern University Press). 
Popkin, S.J. \& Cunningham, M.K. (2002) CHA Relocation Counseling Assessment Final Report, Washington, D.C.: The Urban Institute.

Quigley, J.M. \& Weinberg, D.H. (1977) Intra-Urban Residential Mobility: A Review and Synthesis, International Regional Science Review, 2(2), pp. 41-66.

Rosen, E. (2015) Rigging the Rules of the Game: How Landlords Geographically Sort LowIncome Renters, City \& Community, 13(4), pp. 310-340.

Rosenbaum, J.E. (1993). Closing the Gap: Does Residential Integration Improve the Employment and Education of Low-Income Blacks? In: Lawrence B. Joseph (Ed) Affordable Housing and Public Policy: Strategies for Metropolitan Change, pp.223-258 (Chicago: University of Chicago, Center for Urban Research and Policy Studies).

Rosenbaum, J.E. (1995) Changing the Geography of Opportunity by Expanding Residential Choice: Lessons from the Gautreaux Program, Housing Policy Debate, 6(1), pp. 231-269.

Rosenbaum, J.E., Popkin, S.J., Kaufman, J.E, \& Rusin, J. (1991) Social Integration of LowIncome Black Adults in Middle-Class White Suburbs, Social Problems, 38(4), pp. 448-461.

Rosenbaum, J.E., Reynolds, L. \& DeLuca, S. (2002) How do Places Matter? The Geography of Opportunity, Self-Efficacy and a Look Inside the Black Box of Residential Mobility, Housing Studies, 17(1), pp. 71-82.

Rossi, P.H. (1955) Why Families Move: A Study in the Social Psychology of Urban Residential Mobility (Glencoe, IL: Free Press).

Rossi, P.H. \& Shlay, A.B. (1982) Residential Mobility and Public Policy Issues: "Why Families Move" Revisited, Journal of Social Issues, 38(3), pp. 21-34.

Sanbonmatsu, L., Ludwig, J., Katz, L.F., Gennetian, L.A., Duncan, G.J., Kessler, R.C., Adam, E., McDade, T.W., \& Lindau, S.T. (2011) Moving to Opportunity for Fair Housing Demonstration Program-Final Impacts Evaluation. Prepared for the U.S. Department of Housing and Urban Development. Washington, DC.

Simmons, J.W. (1968) Changing Residence in the City: A Review of Intraurban Mobility, Geographical Review, 58(4), pp. 622-651.

Sink, T. \& Ceh, B. (2011) Relocation of Urban Poor in Chicago: HOPE VI Policy Outcomes, Geoforum, 42(1), pp. 71-82.

Skobba, K. \& Goetz, E.G. (2013). Mobility Decisions of Very Low-Income Households, Cityscape, 15(2), pp. 155-172.

Spain, D. (1990) The Effects of Residential Mobility and Household Composition on Housing Quality, Urban Affairs Quarterly, 25(4), pp. 659-683. 
Speare, A., Jr. (1970) Home Ownership, Life Cycle Stage, and Residential Mobility, Demography, 7(4), pp. 449-458.

Speare, A., Jr. (1974) Residential Satisfaction as an Intervening Variable in Residential Mobility, Demography, 11(2), pp. 173-188.

Stal, G.Y. \& Zuberi, D.M. (2010) Ending the Cycle of Poverty Through Socio-Economic Integration: A Comparison of Moving to Opportunity (MTO) in the United States and the Bijlmermeer Revival Project in the Netherlands, Cities, 27(1), pp. 3-12.

Stockdale, A. \& Catney, G. (2014) A Life Course Perspective on Urban-Rural

Migration: The Importance of the Local Context, Population, Space and Place, 20, pp. 83-98.

Tabachnick, B.G. \& Fidell, L.S. (1989) Using Multivariate Statistics, $2^{\text {nd }}$ ed., (New York: HarperCollins Publishers, Inc.).

Teater, B. (2009) A Place to Call "Home": Exploring the Experiences of Section 8 Housing Choice Voucher Program Recipients in Their Efforts to Find Housing, Families in Society: The Journal of Contemporary Social Services, 90(3), pp. 271-278.

Teernstra, A.B. \& Van Gent, W.P.C. (2012) Puzzling Patterns in Neighborhood Change: Upgrading and Downgrading in Highly Regulated Urban Housing Markets, Urban Geography, 33(1), pp. 91-119.

UCLA Statistical Consulting Group. (n.d.) Introduction to SAS. Available at http://www.ats.ucla.edu/stat/sas/notes2/ (accessed 3 June 2016).

U.S. Census Bureau. (2014) American Community Survey 5-year estimates. Available at: http://factfinder.census.gov/faces/nav/jsf/pages/searchresults.xhtml?refresh=t (accessed 8 May 2016).

U.S. Census Bureau. (2002) Census 2000 SF1 and SF 3. Available at:

http://factfinder.census.gov/servlet/BasicFactsServlet (accessed 14 April 2010)

U.S. Department of Housing and Urban Development. (2002) 24 CFR Part 888, 24 CFR Part 888, Fair Market Rents for the Housing Choice Voucher Program and Moderate Rehabilitation Single Room Occupancy Programs-Fiscal Year 2003, Proposed Rule, Federal Register, 67(100), p. 36307.

U.S. Department of Housing and Urban Development. (2014) Proposed Fair Market Rents for the Housing Choice Voucher Program, Moderate Rehabilitation Single Room Occupancy Program and Other Programs Fiscal Year 2015. Available at: https://www.federalregister.gov/articles/2014/08/15/2014-19390/proposed-fair-market-rentsfor-the-housing-choice-voucher-program-moderate-rehabilitation-single (accessed 9 January 2015). 
Varady, D.P. (2010) What Should Housing Vouchers do? A Review of the Recent

Literature, Journal of Housing and the Built Environment, 25(4), pp. 391-407.

Varady, D.P. \& Preiser, W.F.E. (1998) Scattered-Site Housing and Housing Satisfaction, Journal of the American Planning Association, 64(2), pp. 189-207.

Varady, D.P. \& Walker, C.C. (2007) Neighborhood Choices: Section 8 Housing Vouchers and Residential Mobility (New Brunswick, NJ: Center for Urban Policy Research, Rutgers University).

Varady, D.P. \& Walker, C.C. (2003) Housing Vouchers and Residential Mobility, Journal of Planning Literature, 18(1), pp. 17-30.

Walter, R. J., Li, Y., \& Atherwood, S. (2015) Moving to Opportunity? An Examination of Housing Choice Vouchers on Urban Poverty Deconcentration in South Florida, Housing Studies, 30(7), pp. 1064-1091.

Warner, C. \& Sharp, G. (2016) The Short- and Long-Term Effects of Life Events on Residential Mobility, Advances in Life Course Research, 27, pp. 1-15.

Woolf, L.M. (1998). Theoretical Perspectives Relevant to Developmental Psychology. Available at: http://faculty.webster.edu/woolflm/perspectives.html (accessed 22 May 2016)

\section{Endnotes}

This research uses data from the voucher holder/head of household to represent the household (i.e. individual characteristics and perceptual measures are based on the voucher holder responses to the study survey as well as data in client files). The exception is income which includes all reported income earned by household members.

2 The OCHA voucher holder data file contributed age, income, gender, race, ethnicity, and presence of a dependent (a proxy for the presence of children in the home) variables, while the survey data supplied marital status, education, length of residence, mobility status (the dependent variable), and the indicators for the neighborhood satisfaction index. The 2000 U.S. Decennial Census (U.S. Census Bureau, 2002) provided the neighborhood level (census tract) data used in the neighborhood economic conditions index.

3 We chose to focus on neighborhood satisfaction, rather than the broader concept of residential satisfaction, for two reasons. First, public policy has focused primarily on neighborhood quality when promoting choice and mobility. Second, our data included perceptual and actual measures for neighborhood quality, but did not include precise, actual housing quality measures at the individual household level.

4 Prior to the logistic regression analyses, the data were inspected using common diagnostic techniques. As a result, three of the five continuous, independent variables were transformed using a natural log (age and overcrowding) or a square root transformation (annual household income) to address positive skewness of their distributions (Tabachnick and Fidell, 1989). The dichotomous variables all have sufficient variation for analysis, including mobility, the dependent variable, which has a mean of .31 (see Table 1).

5 Neighborhood researchers in the U.S. tend to use census tract boundaries to represent the neighborhood. However, there is evidence that this may not be the appropriate level for all neighborhood research (see Hipp, 2007). We acknowledge this concern because we use census tract indicators for actual neighborhood quality. Voucher holders used their own understanding of their neighborhood for perceived neighborhood quality (satisfaction indicators).

6 We thank the editor for this comment. 
7 The non-significant result for age ${ }^{2}$ may be a result of the population under study (renters, voucher holders) or it could be that a significant result is expected in a life course model with longitudinal data including life change events, but not in a cross-sectional data set as used in this study.

8 Statistical programs typically do not provide standardized regression coefficients (SRC) for logistic regression. Even in the rare case where they may be provided by the statistics program, the program may include only the partial SRCs (King, 2007).

9 It is possible that people are satisfied with their neighborhood because they have lived there a longer time and are comfortable with it or, equally plausible, they may be satisfied with their neighborhood over time so they live there longer or both. Thus, endogeneity could be an issue between length of residence and neighborhood satisfaction. Endogeneity may be addressed with an instrumental variable approach if such a variable is available, but as if often the case, we did not have a suitable instrument to include in the analysis. Because length of residence is not of substantive importance to our study's objectives, we are not concerned that endogeneity may bias the coefficient for length of residence. However, given the coefficient is statistically significant, it is necessary to recognize the potential endogeneity issue, so that the result is not naively interpreted.

10 Generally, the federal government sets Fair Market Rent (FMR) for regions/counties, usually at the $40^{\text {th }}$ percentile of the rent in the area, and the rent subsidy for the area is set by a local housing authority (LHA) with its established payment standard; the subsidy is paid by the LHA directly to landlords. Voucher holders may pay more than FMR (although in reality, not much more), but the cost above FMR must be paid by the voucher holder from his own resources.

11 Voucher holders are given a time limit for finding a suitable (in terms of cost and conditions) unit. 